\title{
Sociodemographic and geospatial associations with community-associated methicillin-resistant Staphylococcus aureus (CA-MRSA) infections in a large Canadian city: an 11 year retrospective study
}

Victoria C. Gill', Irene Ma², Maggie Guo ${ }^{2,6}$, Dan B. Gregson ${ }^{2,3,6}$, Christopher Naugler ${ }^{2,4,5,6}$ and Deirdre L. Church ${ }^{2,3,6^{*}}$ (1)

\begin{abstract}
Background: The first Canadian outbreak of community-associated methicillin-resistant Staphylococcus aureus (CA-MRSA) was identified in 2004 in Calgary, Alberta. Using a novel model of MRSA population-based surveillance, sociodemographic risk associations, yearly geospatial dissemination and prevalence of CA-MRSA infections over an 11 year period was identified in an urban healthcare jurisdiction of Calgary.

Methods: Positive MRSA case records, patient demographics and laboratory data were obtained from a centralized Laboratory Information System of Calgary Laboratory Services in Calgary, Alberta, Canada between 2004 and 2014. Public census data was obtained from Statistics Canada, which was used to match with laboratory data and mapped using Geographic Information Systems.
\end{abstract}

Results: During the study period, $52.5 \%$ of positive MRSA infections in Calgary were CA-MRSA cases. The majority were CMRSA10 (USA300) clones (94.1\%; $n=4255)$, while the remaining case $(n=266)$ were CMRSA7 (USA400) clones. Period prevalence of CMRSA10 increased from 3.6 cases/100000 population in 2004, to 41.3 cases/100000 population in 2014. Geospatial analysis demonstrated wide dissemination of CMRSA10 annually in the city. Those who are English speaking $(R R=0.05, p<0.0001)$, identify as visible minority Chinese $(R R=0.09, p=0.0023)$ or visible minority South Asian ( $R R=0.25, p=0.015)$, and have a high median household income ( $R R=0.27, p<0.0001$ ) have a significantly decreased relative risk of CMRSA10 infections.

Conclusions: CMRSA10 prevalence increased between 2004 and 2007, followed by a stabilization of cases by 2014. Certain sociodemographic factors were protective from CMRSA10 infections. The model of MRSA populationsurveillance and geomap outbreak events can be used to track the epidemiology of MRSA in any jurisdiction.

Keywords: CA-MRSA, CMRSA10, Geospatial analysis, Laboratory medicine

\footnotetext{
* Correspondence: Deirdre.Church@albertapubliclabs.ca

${ }^{2}$ Department of Pathology and Laboratory Medicine Cumming School of

Medicine, University of Calgary, 3535 Research Rd NW, Calgary, Alberta T2L

$2 \mathrm{~K} 8$, Canada

${ }^{3}$ Department of Medicine, Cumming School of Medicine, University of

Calgary, 3330 Hospital Drive NW, Calgary, Alberta T2N 4N1, Canada

Full list of author information is available at the end of the article
}

(c) The Author(s). 2019 Open Access This article is distributed under the terms of the Creative Commons Attribution 4.0 International License (http://creativecommons.org/licenses/by/4.0/), which permits unrestricted use, distribution, and reproduction in any medium, provided you give appropriate credit to the original author(s) and the source, provide a link to the Creative Commons license, and indicate if changes were made. The Creative Commons Public Domain Dedication waiver (http://creativecommons.org/publicdomain/zero/1.0/) applies to the data made available in this article, unless otherwise stated. 


\section{Background}

Methicillin-resistant Staphylococcus aureus (MRSA) was initially associated with infections acquired in hospital and healthcare environments. In the 1990s, communityassociated MRSA (CA-MRSA) cases were reported worldwide [1]. Since then, CA-MRSA has subsequently become the leading manifestation of MRSA infection [2], occurring in many hospital and community settings [1]. Despite having less resistance to other antimicrobial classes than hospital-associated MRSA (HA-MRSA) [3], CA-MRSA has been able to colonize and infect humans effectively, leading to it becoming the dominant $S$. aureus strain in multiple settings [4].

Although there are a variety of CA-MRSA clones, CMRSA10 (USA300) is the predominant cause of skin and soft tissue infection in the United States [4]. The first outbreak of CA-MRSA in Canada was due to the CMRSA10 clone, and was documented in the Calgary Health Region in 2004, when physicians at a local corrections facility noticed an increase in soft tissue infections [5]. A rapid growth in CMRSA10 infections was documented as the number of culture-positive infections climbed from only seven cases between 2002 and 2003, to 42 cases in 2004. It was reported that individuals with a history of illicit drug use, homelessness or recent incarceration were associated with highest risk of infection and accounted for $70 \%$ of cases [5].

Community-associated MRSA lacks the traditional risk factors associated with HA-MRSA making identification of those at risk and the monitoring of its spread throughout the general population even more difficult. As the name suggests, CA-MRSA are predominantly acquired in the community, and can spread within families, prisons and sports teams due to close physical contacts (especially those resulting in skin abrasions), the use of shared sanitary facilities, crowded living conditions, poor hygiene, and have been in contact with contaminated objects and surfaces. Transmission of HAMRSA on the other hand is nosocomial, and its spread is often minimal among household contacts. Patients with CA-MRSA infections are typically younger, and previously healthy when compared to HA-MRSA patients, as patients with HA-MRSA infections are generally elderly, have been hospitalized for prolonged periods, in intensive care units, have indwelling lines or devices, and/or are on long-term antibiotics $[1,2,6]$.

Implementation of control strategies for those at highest risk of CA-MRSA in the general population has proven to be challenging. The objective of this study was to use a new model for population-based MRSA surveillance by combining laboratory data, publically available census, and geographic information to identify sociodemographic risk associations, geomap yearly CAMRSA spread, and document the prevalence of all
MRSA cases between 2004 and 2014 within a Canadian healthcare jurisdiction.

\section{Methods \\ Laboratory data and study population}

Calgary Laboratory Services (CLS) was created in 1996 and has since then remained the sole diagnostic microbiological testing laboratory in Calgary, Alberta [7], thereby offering an excellent opportunity to investigate the spread of MRSA within a population. Utilizing a comprehensive record of all laboratory results, all positive MRSA cultures from January 1, 2004 to December 31, 2014 were identified. Samples were obtained from patients presenting with symptoms of infection to any Alberta Health Services (AHS) facilities or private health offices including, but not limited to, outpatient clinics, hospitals, general practitioners, and community clinics. Microbiology samples from all sites are processed and analyzed centrally by CLS. All clinical isolates of $S$. aureus were screened and confirmed for the presence of methicillin-resistance according to Clinical and Laboratory Standards Institute antibiotic susceptibility testing guidelines with annual updates to CLS procedures. MRSA positive samples were identified and mecA presence confirmed by polymerase chain reaction (PCR), as described previously [8]. During the study period of 2004 to 2010, positive MRSA cultures were routinely typed using pulse-field gel electrophoresis (PFGE) with restriction endonuclease Sma1, per standard protocol [9]. From 2010 onwards, spa typing was used, as described previously [10].

Records of clinical MRSA cases were retrieved from the CLS database, and any records with missing Provincial Health Numbers (PHN) were excluded from analysis, as the PHN allows for further linkage to obtain the age and gender of each patient. Similar to other studies $[11,12]$, only the first positive MRSA test result was used in individuals with multiple MRSA test results in any given calendar year, as subsequent MRSA infections have been shown to often be of the original strain of infection in an individual [13]. Inconclusive MRSA cases, and results from all asymptomatic screening tests were excluded from the analysis.

\section{Census data and geospatial mapping}

For the Census years within the study period (2006, 2011), population counts were obtained from Statistics Canada for Calgary [14-16]. For the non-Census years between 2004 and 2014, population estimates were obtained from census population counts from the census years surrounding the study period [14-17], where continuous growth between these values was assumed.

Patient PHN was also used as the linking variable to obtain patient postal codes from an Alberta Health 
Services database. Postal codes were converted and linked to Statistics Canada's corresponding census dissemination areas (CDAs) to limit our population to cases within the city of Calgary. Each CDA accounts for 400 to 700 individuals, and are the smallest polygons for which census data are available in Statistics Canada [14], thereby adjusting for the population density. Using ArcGIS (version 10.3), CMRSA10 case maps for each year between 2004 and 2014 were created, as described previously [18]. All potentially identifying information, such as patient PHN and postal codes, were removed for the analysis of the study.

\section{Statistical analysis}

Period prevalence was calculated to demonstrate the changing burden of all MRSA in Calgary, as the city's population was collected from Statistics Canada for the census years, and estimated for the non-census years. Due to the infectious nature of MRSA, the entire population of Calgary was considered to be at risk therefore providing our denominator. Summary statistical methods were used to determine the yearly demographics of CA-MRSA infections in Calgary.

A generalized Poisson mixed model was used to examine associations between sociodemographic variables (independent variable) and positive CMRSA10 case rate per CDA (dependent variable) in 2011, as described previously [19-21]. This model was chosen to account for the strata size through the CDAs, where the rate over the CDA was assumed to be constant, and the testing data was independent. Sociodemographic census data was accessed from Statistic Canada's 2011 Canadian Household Survey for CDA [22], the most recent Census during the study period, where the following sociodemographic variables were included: English speaking, employment rate, education level (having at least some university education), recent immigration status (within the last 5 years), Indigenous status (First Nations, Inuit, and Métis), and the three largest visible minority groups in Canada: 'Chinese,' 'South Asian', and 'Black'. Median household income (MHI) was also explored and reported for each increase of $\$ 100,000 \mathrm{CAD}$. The reported relative risks (RR) refer to the independent contribution of each sociodemographic variable when compared to its respective reference state. For example, all non-native English speakers from the 2011 census not included in the study was used as a reference state for the "English speaking" sociodemographic variable. $P<0.05$ was deemed statistically significant (SAS v. 9.4 software).

\section{Results}

Between January 1, 2004 and December 31, 2014, 16,553 clinical MRSA infections were documented in the CLS database from all sites, including but not limited to community, inpatient, emergency, and outpatient settings. Of these, 13, 878 records had an Alberta PHN, which allowed for further linkage to provincial residential postal codes, age, and sex. Residents of the city of Calgary accounted for 9656 of these results, where 8611 of those records were matched with molecular typing results. Community-associated MRSA infections accounted for 4521 of these records, of which, the majority (94.1\%) were CMRSA10 cases (Fig. 1).

The prevalence of all MRSA cases in the city of Calgary rose from 22.2 cases/100000 population, to 81 cases/100000 population in 2004 and 2014, respectively. Using Statistics Canada's census data, CA-MRSA had a prevalence of 4.8 cases/100000 population in 2004, and rose rapidly to $53.19 / 100000$ in 2007 , followed by stabilizing to $44.3 / 100000$ by 2014 . The prevalence of CMRSA7 (USA400 clone) ranged between 1.2 and 3 cases per 100,000 population during the study period, while CMRSA10 began with a prevalence of 3.6 cases/ 100000 population in 2004, and increased to 41.3 cases/ 100000 population in 2014 (Table 1). The median age of all CA-MRSA cases was approximately 41 years, and more than half $(n=2802)$ of the infections were observed in males (Table 2).

As $94.1 \%$ of CA-MRSA cases were CMRSA10 in Calgary, geographical dissemination and sociodemographic associations were analyzed for this clone. Geospatial analysis revealed that in 2004, CMRSA10 infections in the city of Calgary were already widely disseminated across the city (Fig. 2). In 2005, the number of cases rapidly increased, with regions of up to 10 cases per cluster observed in the downtown region, and spreading in the communities along the Bow River, extending further east and to the southern part of the city. Cases continued to spread and disseminate outwards in all directions as prevalence of CMRSA10 increased in 2007. The downtown core and just east of the Bow River visually appear to be focal regions for CMRSA10 cases, with multiple regions of up to 26 cases per cluster (see Additional file 1 for a video representation of CMRSA10 spread throughout Calgary annually from 2004 to 2014). Although there was a relative stabilization of positive CMRSA10 cases by 2014, there was a substantial increase of clustered cases in the entire downtown region, to a far greater extent than observed in previous years (Fig. 2).

A generalized Poisson mixed model revealed that certain sociodemographic variables, such as being an English speaker, of a visible minority Chinese, or of a visible minority South Asian were at a significantly lower risk of CMRSA10 infections in Calgary, Alberta. For every $\$ 100,000$ CAD increase in median household income, the risk of having a CMRSA10 infection reduces significantly by $73 \%$. All other sociodemographic associations with CMRSA10 infection in Calgary was not statistically significant (Table 3). 


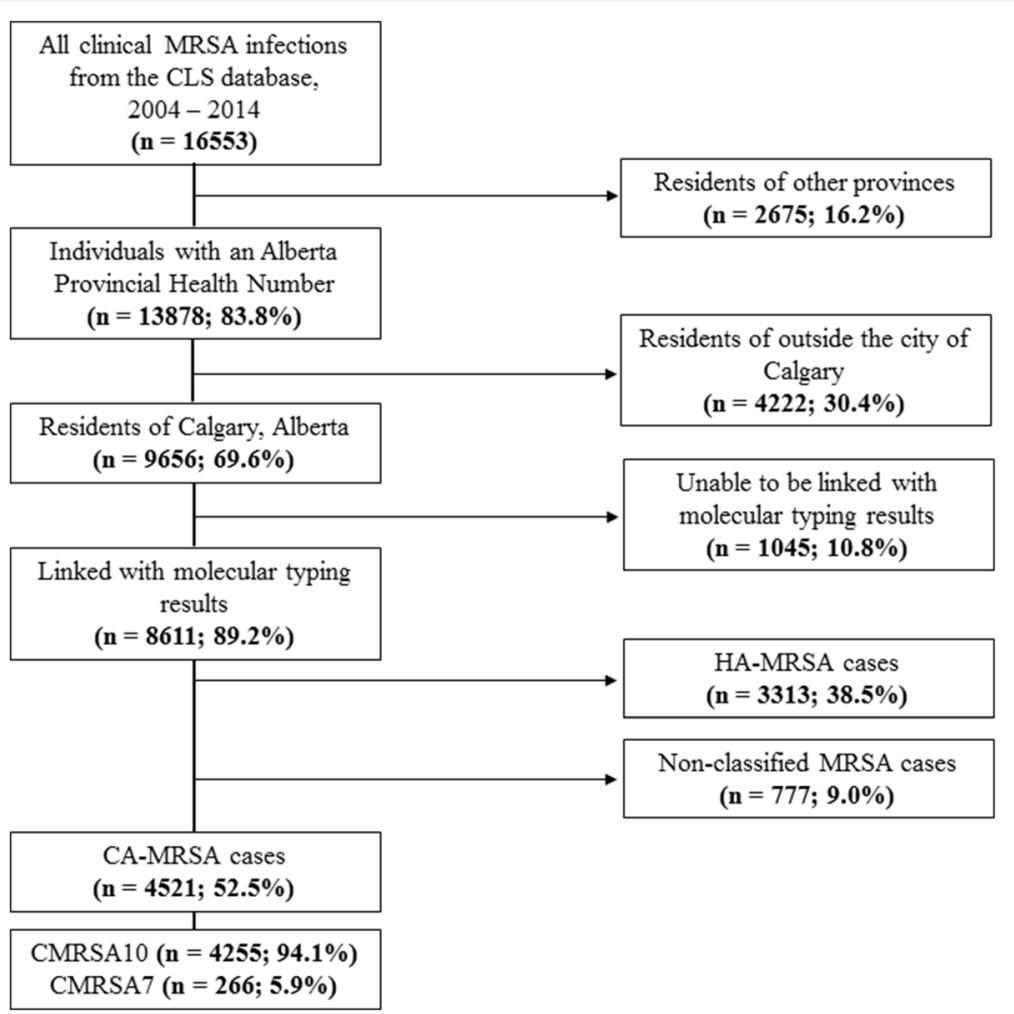

Fig. 1 Flow diagram of inclusion (left) and exclusion (right) criteria of study population (2004-2014)

\section{Discussion}

By utilizing a novel method of combining laboratory data, publically available census data, and geographic information, the sociodemographic risk associations of the most prevalent type of CA-MRSA, CMRSA10 (USA300 clone), in the general population of over 1.4 million individuals in a Canadian urban healthcare jurisdiction that included community, inpatient and outpatient settings were reported here. An update of the yearly prevalence of all MRSA, and geospatial dissemination of CMRSA10 over an 11 year period since the initial Canadian outbreak in 2004 in Calgary, Alberta, Canada were also reported.

There has been documented decreases of CAMRSA in some North American populations up to 2011 [23, 24]. However, in this study, the prevalence of CA-MRSA and USA300 infections increased drastically from 2004 to 2007, followed by a relative stabilization with minor fluctuations of prevalence between 2007 and 2014. One possible explanation for the relative stabilization of CA-MRSA infections is

Table 1 Period prevalence (cases per 100,000 population) of all MRSA cases in Calgary, Canada

\begin{tabular}{lllllll}
\hline Year & Population of Calgary & All MRSA & HA-MRSA & CA-MRSA & CMRSA7 (USA400) & CMRSA10 (USA300) \\
\hline 2004 & 943,322 & 22.16 & 15.27 & 4.77 & 1.17 & 3.60 \\
2005 & 965,804 & 46.08 & 25.16 & 17.71 & 1.66 & 16.05 \\
2006 & $988812^{\mathrm{a}}$ & 70.69 & 35.40 & 30.64 & 2.12 & 28.52 \\
2007 & $1,009,656$ & 90.53 & 30.41 & 53.19 & 2.28 & 50.91 \\
2008 & $1,030,940$ & 84.87 & 26.58 & 49.28 & 2.04 & 47.24 \\
2009 & $1,052,672$ & 92.53 & 31.54 & 51.77 & 1.42 & 50.35 \\
2010 & $1,074,862$ & 86.80 & 37.96 & 44.94 & 3.16 & 41.77 \\
2011 & $1096833^{\mathrm{a}}$ & 77.31 & 29.63 & 40.94 & 2.37 & 38.57 \\
2012 & $1,123,937$ & 77.05 & 30.07 & 40.39 & 2.49 & 37.90 \\
2013 & $1,151,712$ & 77.45 & 24.40 & 43.67 & 3.04 & 40.64 \\
2014 & $1,180,172$ & 81.01 & 26.35 & 44.32 & 3.05 & 41.27
\end{tabular}

apopulation of Calgary was derived from Statistics Canada's census data for 2006 and 2011 [15, 17] 
Table 2 Yearly demographics of community-associated MRSA (CA-MRSA) cases in Calgary, Alberta, Canada

\begin{tabular}{lllll}
\hline Year & Total number of CA-MRSA cases $(\mathrm{n})$ & Median Age (lower quartile, upper quartile) & Number of Females (\%) & Number of Males (\%) \\
\hline 2004 & 45 & $36.4(25.5,50.9)$ & $19(42.4)$ & $26(57.8)$ \\
2005 & 171 & $38.9(29.3,47.8)$ & $52(30.4)$ & $119(69.6)$ \\
2006 & 303 & $41.2(29.4,51.4)$ & $100(33.0)$ & $203(67.0)$ \\
2007 & 537 & $40.6(28.0,50.6)$ & $188(35.0)$ & $349(65.0)$ \\
2008 & 508 & $40.6(26.9,51.1)$ & $201(39.6)$ & $307(60.4)$ \\
2009 & 545 & $43.7(30.2,54.4)$ & $231(42.4)$ & $314(57.6)$ \\
2010 & 483 & $41.0(26.7,55.9)$ & $199(41.2)$ & $284(58.8)$ \\
2011 & 449 & $41.3(27.8,55.3)$ & $193(43.0)$ & $256(57.0)$ \\
2012 & 454 & $40.3(26.5,57.1)$ & $173(38.1)$ & $281(61.9)$ \\
2013 & 503 & $41.1(28.2,54.5)$ & $185(36.8)$ & $318(63.2)$ \\
2014 & 523 & $43.2(27.9,56.7)$ & $178(34.0)$ & $1719(38.0)$ \\
\hline
\end{tabular}

the introduction of a formal laboratory surveillance program in Alberta in 2005 after the initial outbreak [25], resulting in increased testing for MRSA infections that normally would not require culturing and could be treated without antibiotic use. As CA-MRSA became increasingly prevalent in our population, this excess culturing may have diminished and resulted in the levelling off to only include clinical infections that require culturing [26]. However, CA-MRSA is still prevalent by the end of the study period, which was expected due to its infectious nature, and investigation into control and prevention strategies are warranted.

Similar to other studies $[2,11]$, CA-MRSA cases in Calgary, Alberta, affected more males than females, as well as younger individuals. The sex difference observed is unlikely due to an increased biologic susceptibility to CA-MRSA in males, but rather, different exposure to transmission risks between males and females for CAMRSA, as demonstrated by USA300 affecting more females in a study by Bratu, et al. [27].

Through the analysis of molecular typing results, it became clear that CMRSA10, not CMRSA7, drove the increase of CA-MRSA cases in our population. These results are consistent with studies that find CMRSA10 (USA300) as the predominant clone in urban centres $[11,27]$, while CMRSA7 (USA400) is the leading clone in rural or remote locations $[28,29]$. Some possibilities for the difference in infection rates between the two clones may include competition from CMRSA10 in our population, or different, as yet unidentified, individual and societal risk factors playing a role between clones.

As CMRSA10 was the predominant clone in CAMRSA cases in Calgary, geospatial mapping and sociodemographic associations were further investigated for this clone. One of the most striking findings from the maps of CMRSA10 cases was the rapid and widespread dissemination across Calgary. This wide distribution of cases over a geographically large area demonstrated that, while CA-MRSA may be acquired in high risk areas, this spread may result in further transmission and reservoirs of infection in other communities. The geographical spread of cases across Calgary may be indicative of hotspots of transmission in areas where large proportions of individuals gather and cross paths (e.g.: in the downtown core), before spreading out across the city. As supported by the initial outbreak of CMRSA10 in 2004 that was connected to those with a history of illicit drug use, homelessness or recent incarceration [5], the clustered cases appear to be focused in the downtown region containing multiple shelters that service those who are homeless or at risk for homelessness, or affected by alcohol and drug dependencies.

Although we are not able to draw inferences of multiple combinations of sociodemographic associations with positive CMRSA10 case rate, as each variable was analyzed as an independent contribution, our model demonstrated that certain sociodemographic variables, such as English speaking, being of visible minority Chinese or South Asian, or having a high median household income, were associated with a decreased risk of acquiring CMRSA10. The relationship between income and disease risk was as predicted as increased income is commonly associated with improved health, living conditions and decreased residential crowding, which would likely limit the risk of CA-MRSA transmission $[2,30]$. Risk factors such as homelessness and incarceration, as documented in 2004 in our population, are expected to decrease with increased income.

Those who identify themselves as native English speakers in the Census also demonstrated a decreased risk for acquiring CMRSA10 compared to those who do not identify as native English speakers. One reason could 


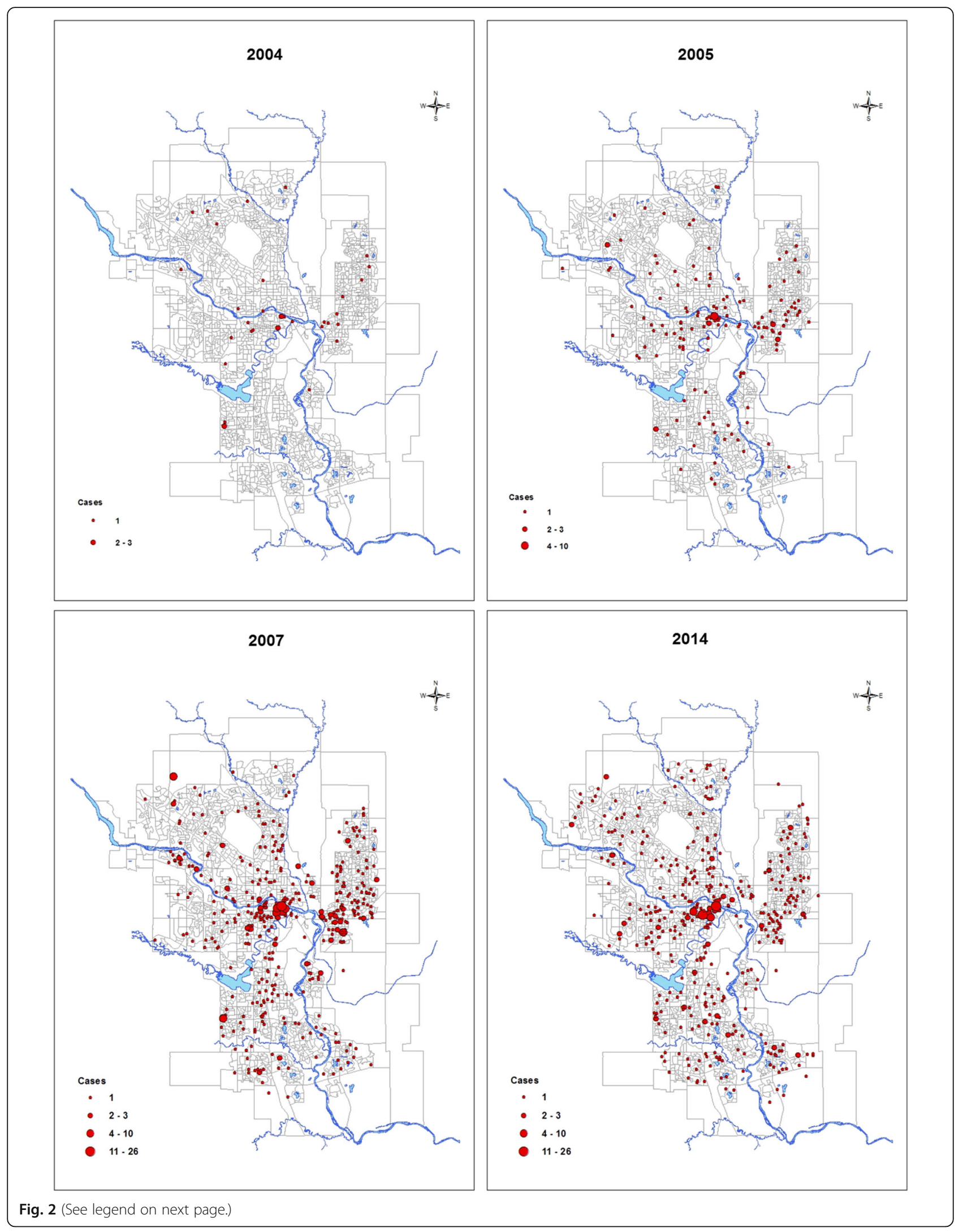


(See figure on previous page.)

Fig. 2 Geospatial dissemination of CMRSA10 cases in Calgary, Alberta during select years of the study period. In 2004 (top left), small clusters of CMRSA10 infections in the city of Calgary were already widely disseminated across the city, including the downtown city centre (just south of the Bow River that passes through the city from west to east) and the northern half of the city. Two clusters of up to 3 cases were located both in downtown and the southwest quadrant of the city. In 2005 (top right), the number of cases rapidly increased, spreading in the communities along the Bow River, extending further east and to the southern part of the city. Cases continued to spread and disseminate outwards in all directions as prevalence of CMRSA10 increased in 2007 (bottom left). The downtown core and just east of the Bow River visually appear to be focal regions for CMRSA10 cases, with multiple regions of up to 26 cases per cluster. In 2014 (bottom right), there appeared to be a relative stabilization of positive cases since 2007 . For a video of CMRSA10 spread throughout Calgary annually between 2004 and 2014, please see Additional file 1

be attributed to the ability for the patient to understand promoted behaviours and health interventions that are aimed at reducing risk by healthcare providers [31].

Visible minority Chinese status and visible minority South Asian status were variables that presented with decreased risk of CMRSA10. We did not expect to see any evidence in these variables reflecting either increased, or decreased risk. It is unlikely that these variables were protective factors against CMRSA10, but was a surrogate marker for a variable that were unmeasured.

Although studies have shown that Indigenous populations [1, 32, 33] and African-Americans [27, 34] are more likely to be at risk for CA-MRSA infections, our analysis did not show significant associations between CMRSA10 cases with Indigenous or the visible minority Black populations of Calgary. However, it has been shown that Canadian Indigenous populations are more likely associated with CMRSA7 clone, rather than CMRSA10 $[28,35,36]$. As there is no biological plausibility for certain ethnicities to be at an increased risk for CA-MRSA infections, this may be reflective of larger societal differences between our population and those in other studies.

\section{Limitations}

As routine culture is not recommended in current guidelines [26], along with the lack of population screening strategies, only patients with microbiologically confirmed infections were included, while asymptomatic carriers were excluded in our analysis, which may have resulted in an underestimation of the true prevalence of CA-MRSA infection within Calgary. Furthermore, as any patient without a Provincial Health Number were excluded in our study analysis (temporary workers and visitors from outside of Alberta), this may have also contributed to the underestimation of CA-MRSA prevalence within the city of Calgary. Although this proportion would likely be small, the patients excluded from our study criteria receiving acute medical care in Calgary would represent an important population regarding the spread and transmission of CA-MRSA. Despite these limitations, the data likely closely reflects the true prevalence of more serious CA-MRSA infections where routine culture is strongly recommended in guidelines [26].

Another limitation of this project was that the data obtained and analysis performed were at the population level. The ecological fallacy that what holds true at a population level also holds true at an individual level mandates cautious interpretation of our results. While our data appear to support the association of documented individual risk factors with CA-MRSA infection, we cannot confirm that these factors are the cause of what we are observing nor extrapolate these individual risk factors to communities in other jurisdictions.

The system that we used to obtain the residential data used the listed residence at fiscal year-end as the location of record, thus the case location did not necessarily indicate where CMRSA10 infections were acquired, nor does it indicate the residence at the time of infection if the individual moved within the calendar year. The

Table 3 Generalized Poisson mixed model analysis of sociodemographic associations with CMRSA10 cases in Calgary in 2011

\begin{tabular}{llll}
\hline Sociodemographic Variables & Risk Ratio (RR) & $95 \% \mathrm{Cl}$ & \multicolumn{1}{c}{-value } \\
\hline English speaking & 0.05 & $0.01-0.18$ & 0.0001 \\
Recent immigrant (within 5 years) & 0.65 & $0.11-3.96$ & 0.6385 \\
Indigenous status (First Nations, Inuit, Métis) & 0.61 & $0.05-7.21$ & 0.6912 \\
Visible minority Chinese & 0.09 & $0.02-0.42$ & 0.0023 \\
Visible minority South Asian & 0.25 & $0.08-0.76$ & 0.015 \\
Visible minority Black & 1.03 & $0.15-6.86$ & 0.9772 \\
Median household income (\$100,000 CAD) & 0.27 & $0.19-0.39$ & 0.0 .0001 \\
Employment rate & 0.45 & $0.16-1.23$ & 0.1196 \\
Education level (at least some university education) & 1.00 & $0.36-2.72$ & 0.994 \\
\hline
\end{tabular}


spread of cases observed from our maps could be different from the locations where risk factors are, and where transmission is occurring. Despite the limitations they still provide valuable insight to the spread and distribution of CMRSA10 in Calgary over 11 years.

\section{Conclusions}

Although the results of this study focused on an urban healthcare jurisdiction within Canada, the method of combining various databases from Laboratory Information Systems, publically available censuses, and Geographic Information Systems can be utilized in any jurisdiction globally to perform MRSA surveillance and geomap outbreak events. Sociodemographic risk association results from this study can inform healthcare providers to assist in future testing strategies, targeted interventions and control measures in our population. Enhanced efforts should be made to control and prevent CA-MRSA spread.

\section{Additional file}

Additional file 1: Video S1. Yearly spread of CMRSA10 (USA300) positive cases in the city of Calgary, between 2004 and 2014. (MP4 1200 kb)

\section{Abbreviations}

AHS: Alberta Health Services; CA-MRSA: Community-Associated MethicillinResistant Staphylococcus aureus; CDA: Census dissemination area; CLS: Calgary Laboratory Services; HA-MRSA: Hospital-Associated MethicillinResistant Staphylococcus aureus; MHI: Median household income; MRSA: Methicillin-Resistant Staphylococcus aureus; PCR: Polymerase chain reaction; PHN: Provincial health number; RR: Relative risk

\section{Acknowledgements}

The authors would like to thank Dr. Tarah Lynch for her assistance.

\section{Authors' contributions}

All authors (VCG, IM, DBG, MG, CN, DLC) made substantial contributions to: the conception and design of the study, analysis and interpretation of the data, revising the article critically for important content, and gave final approval of the version to be submitted. MG made substantial contributions to the acquisition of the data. VCG and IM drafted the article. All authors have read and approved the final manuscript.

\section{Funding}

This study was supported by the Canadian Institutes of Health Research (CIHR) Foundation Scheme to CN, grant number: RN254781-333204. The funding body did not have a role in any part of this study.

\section{Availability of data and materials}

The datasets generated during and/or analyzed during the current study are not publically available due to confidentiality and ethics review board restrictions, but are available from the corresponding author on reasonable request.

\section{Ethics approval and consent to participate}

Ethics approval for the project was obtained from both the Conjoint Health Research Ethics Board at the University of Calgary (Ethics ID: REB150629_REN2) and the London School of Hygiene and Tropical Medicine MSC Research Ethics Committee (Ethics ID: 10732). Waiver of consent for this study was received from the University of Calgary Conjoint Health Research Ethics Board (Ethics ID. REB15-0629 REN2) due to the impracticality to contact a substantial proportion of the population in the Calgary Health Region to ask consent for access to their secondary data after a considerable time has elapsed, which is justified given the negligible risk this research poses.

\section{Consent for publication}

Not applicable.

\section{Competing interests}

The authors declare they have no competing interests.

\section{Author details}

${ }^{1}$ London School of Hygiene and Tropical Medicine, Keppel Street, London WC1E 7HT, UK. ${ }^{2}$ Department of Pathology and Laboratory Medicine Cumming School of Medicine, University of Calgary, 3535 Research Rd NW Calgary, Alberta T2L 2K8, Canada. ${ }^{3}$ Department of Medicine, Cumming School of Medicine, University of Calgary, 3330 Hospital Drive NW, Calgary, Alberta T2N 4N1, Canada. ${ }^{4}$ Department of Family Medicne, Cumming School of Medicine, University of Calgary, 3330 Hospital Drive NW, Calgary, Alberta T2N 4N1, Canada. ${ }^{5}$ Department of Community Health Sciences, Cumming School of Medicine, University of Calgary, 3330 Hospital Drive NW, Calgary, Alberta T2N 4N1, Canada. ${ }^{6}$ Alberta Public Laboratories, 3535 Research Road NW, Calgary, Alberta T2L 2K8, Canada.

Received: 11 December 2018 Accepted: 13 June 2019

Published online: 09 July 2019

\section{References}

1. David MZ, Daum RS. Community-associated methicillin-resistant Staphylococcus aureus: epidemiology and clinical consequences of an emerging epidemic. Clin Microbiol Rev. 2010;23:616-87. https:/doi.org/10.1128/CMR.00081-09.

2. Hawkes M, Barton M, Conly J, Nicolle L, Barry C, Ford-Jones EL. Communityassociated MRSA: superbug at our doorstep. CMAJ. 2007;176:54-6. https:// doi.org/10.1503/cmaj.061370

3. Allen UD. Public health implications of MRSA in Canada. CMAJ. 2006:175: 161. https://doi.org/10.1503/cmaj.060480.

4. King MD, Humphrey BJ, Wang YF, Kourbatova EV, Ray SM, Blumberg HM. Emergence of community-acquired methicillin-resistant Staphylococcus aureus USA 300 clone as the predominant cause of skin and soft-tissue infections. Ann Intern Med. 2006;144:309-17.

5. Gilbert M, MacDonald J, Gregson D, Siushansian J, Zhang K, Elsayed S, et al. Outbreak in Alberta of community-acquired (USA300) methicillin-resistant Staphylococcus aureus in people with a history of drug use, homelessness or incarceration. CMAJ. 2006;175:149-54. https://doi.org/10.1503/cmaj.051565.

6. Cooke FJ, Brown NM. Community-associated methicillin-resistant Staphylococcus aureus infections. Br Med Bull. 2010;94:215-27. https://doi. org/10.1093/bmb/ldq010.

7. Church DL, Hall P. Centralization of a regional clinical microbiology service: the Calgary experience. Can J Infect Dis. 1999;10:393-402.

8. Hussain Z, Stoakes L, Massey V, Diagre D, Fitzgerald V, El Sayed S, et al. Correlation of oxacillin MIC with mecA gene carriage in coagulase-negative staphylococci. J Clin Microbiol. 2000;38:752-4.

9. Mulvey MR, Chui L, Ismail J, Louie L, Murphy C, Chang N, et al. Development of a Canadian standardized protocol for subtyping methicillin-resistant Staphylococcus aureus using pulsed-field gel electrophoresis. J Clin Microbiol. 2001;39:3481-5. https://doi.org/10.1128/ JCM.39.10.3481-3485.2001.

10. Golding GR, Campbell JL, Spreitzer DJ, Veyhl J, Surynicz K, Simor A, et al. A preliminary guideline for the assignment of methicillin-resistant Staphylococcus aureus to a Canadian pulsed-field gel electrophoresis epidemic type using spa typing. Can J Infect Dis Med Microbiol. 2008:19:273-81.

11. Liu C, Graber CJ, Karr M, Diep BA, Basuino L, Schwartz BS, et al. A population-based study of the incidence and molecular epidemiology of methicillin-resistant Staphylococcus aureus disease in San Francisco, 20042005. Clin Infect Dis. 2008;46:1637-46. https://doi.org/10.1086/587893.

12. Li V, Chui L, Simmonds K, Nguyen T, Golding GR, Yacoub W, et al. Emergence of new CMRSA7/USA400 methicillin-resistant Staphylococcus aureus spa types in Alberta, Canada, from 2005 to 2012. J Clin Microbiol. 2014:52:2439-46. https://doi.org/10.1128/JCM.00505-14.

13. Huang SS, Diekema DJ, Warren DK, Zuccotti G, Winokur PL, Tendolkar S, et al. Strain-relatedness of methicillin-resistant Staphylococcus aureus isolates recovered from patients with repeated infection. Clin Infect Dis. 2008:46: 1241-7. https://doi.org/10.1086/529381. 
14. Statistics Canada. 2006 Census Area Profiles. 2006 Census Popul Stat Canada Cat No 94-575-XCB2006001 n.d. http://www12.statcan.gc.ca/census-recensement/ 2006/dp-pd/prof/rel/Rp-eng.cfm?TABID=2\&LANG=E\&APATH=3\&DETAIL=1\&DIM= 0\&FL=A\&FREE $=1 \& G C=0 \& G I D=775606 \& G K=0 \& G R P=1 \& P I D=89108 \& P R I D=$ 0\&PTYPE $=89103 \& S=0 \& S H O W A L L=$ No\&SUB $=0 \& T e m p o r a l=2006 \& T H E M E=66 \& V I D=$ 0\&VNAMEE=\&VNAMEF=\&D1=0\&D. Accessed Aug 72018.

15. Statistics Canada. Statistics Canada: 2011 Census Profile. Stat Canada Cat No 98-316-XWE 2012. http://www12.statcan.gc.ca/census-recensement/2011/ dp-pd/prof/details/page.cfm?Lang=E\&Geo1=CSD\&Code1=4806016\&Geo2= PR\&Code $2=48 \&$ Data $=$ Count\&SearchText $=$ Calgary\&SearchType $=$ Begins\&SearchPR=48\&B1=All\&Custom=\&TABID=1. Accessed Aug 72018

16. Statistics Canada. Census Profile, 2016 Census. Stat Canada Cat No 98-316X2016001 2017. https://www12.statcan.gc.ca/census-recensement/2016/dppd/prof/details/page.cfm?Lang=E\&Geo1=CSD\&Code1=4806016\&Geo2= CD\&Code2 $=4806 \& D a t a=$ Count $\&$ SearchText $=$ calgary $\&$ SearchType $=$ Begins\&SearchPR=01\&B1=All\&TABID=1. Accessed Aug 72018.

17. Statistics Canada. Population and dwelling counts, for Canada, census metropolitan areas, census agglomerations and census subdivisions (municipalities), 2001 and 1996 censuses - 100\% data. Stat Canada n.d. https://www12.statcan.gc.ca/english/census01/products/standard/popdwell/ Table-CMA-C.cfm?CMA=825. Accessed Aug 72018

18. Baskin L, Abdullah A, Guo M, Naugler C. Use of geospatial mapping to determine suitable locations for patient service centers for phlebotomy services. Am J Clin Pathol. 2015;144:727-30. https://doi.org/10.1309/ AJCP4J1XKDVJIUGS.

19. Crouse A, Sadrzadeh SM, de Koning L, Naugler C. Sociodemographic correlates of fecal immunotesting for colorectal cancer screening. Clin Biochem. 2015;48:105-9. https://doi.org/10.1016/j.clinbiochem.2014.12.004.

20. Griener TP, Naugler C, Chan WW, Church DL. Sociodemographic correlates of urine culture test utilization in Calgary, Alberta. BMC Urol. 2018;18:2. https://doi.org/10.1186/s12894-018-0315-x.

21. Ma I, Guo M, Muruve D, Benediktsson H, Naugler C. Sociodemographic associations with abnormal estimated glomerular filtration rate (eGFR) in a large Canadian city: a cross-sectional observation study. BMC Nephrol. 2018; 19:198. https://doi.org/10.1186/s12882-018-0991-5.

22. Statistics Canada. National Household Survey (NHS) Profile, 2011. Stat Canada Cat No 99-004-XWE 2013. https://www12.statcan.gc.ca/nhs-enm/ 2011/dp-pd/prof/details/page.cfm?Lang=E\&Geo1=CSD\&Code1= 4806016\&Data=Count\&SearchText=calgary\&SearchType=Begins\&SearchPR= $48 \& A 1=A l l \& B 1=A l l \& C$ ustom $=\& T A B I D=1$. Accessed Sept 242018

23. Planet PJ. Life after USA300: the rise and fall of a superbug. J Infect Dis. 2017;215:S71-7. https://doi.org/10.1093/infdis/jiw444.

24. Nichol KA, Adam HJ, Roscoe DL, Golding GR, Lagace-Wiens PRS, Hoban DJ, et al. Changing epidemiology of methicillin-resistant Staphylococcus aureus in Canada. J Antimicrob Chemother. 2013;68:147-55. https://doi.org/10.1093/ jac/dkt026.

25. Webster D, Rennie RP, Brosnikoff CL, Chui L, Brown C. Methicillin-resistant Staphylococcus aureus with reduced susceptibility to vancomycin in Canada. Diagn Microbiol Infect Dis. 2007;57:177-81. https://doi.org/10.1016/ j.diagmicrobio.2006.07.007.

26. Liu C, Bayer A, Cosgrove SE, Daum RS, Fridkin SK, Gorwitz RJ, et al. Clinical practice guidelines by the Infectious Diseases Society of America for the treatment of methicillin-resistant Staphylococcus aureus infections in adults and children. Clin Infect Dis. 2011;52:e18-55. https:/doi.org/10.1093/cid/ciq146.

27. Bratu S, Landman D, Gupta J, Trehan M, Panwar M, Quale J. A populationbased study examining the emergence of community-associated methicillin-resistant Staphylococcus aureus USA300 in new York City. Ann Clin Microbiol Antimicrob. 2006;5:29. https://doi.org/10.1186/1476-0711-5-29.

28. Dalloo A, Sobol I, Palacios C, Mulvey M, Gravel D, Panaro L. Investigation of community-associated methicillin-resistant Staphylococcus aureus in a remote northern community, Nunavut, Canada. Can Commun Dis Rep. 2008;34:1-7.

29. David MZ, Rudolph KM, Hennessy TW, Boyle-Vavra S, Daum RS. Molecular epidemiology of methicillin-resistant Staphylococcus aureus, rural southwestern Alaska. Emerg Infect Dis. 2008;14:1693-9. https://doi.org/10. 3201/eid1411.080381.

30. Mikkonen J, Raphael D. Social determinants of health: the Canadian facts. Toronto: York University School of Health Policy and Management; 2010.

31. Woloshin S, Schwartz LM, Katz SJ, Welch HG. Is language a barrier to the use of preventive services? J Gen Intern Med. 1997;12:472-7. https://doi.org/ 10.1046/J.1525-1497.1997.00085.X
32. Ofner-Agostini M, Simor AE, Mulvey M, Bryce E, Loeb M, McGeer A, et al. Methicillin-resistant Staphylococcus aureus in Canadian aboriginal people. Infect Control Hosp Epidemiol. 2006;27:204-7. https:/doi.org/10.1086/500628.

33. Groom AV, Wolsey DH, Naimi TS, Smith K, Johnson S, Boxrud D, et al. Community-acquired methicillin-resistant Staphylococcus aureus in a rural American Indian community. JAMA. 2001;286:1201. https://doi.org/10.1001/ jama.286.10.1201.

34. Fridkin SK, Hageman JC, Morrison M, Sanza LT, Como-Sabetti K, Jernigan JA, et al. Methicillin-resistant Staphylococcus aureus disease in three communities. N Engl J Med. 2005;352:1436-44. https://doi.org/10.1056/NEJMoa043252.

35. Golding GR, Levett PN, McDonald RR, Irvine J, Quinn B, Nsungu M, et al. High rates of Staphylococcus aureus USA400 infection, northern Canada. Emerg Infect Dis. 2011;17:722-5. https://doi.org/10.3201/eid1704.100482.

36. Mulvey MR, MacDougall L, Cholin B, Horsman G, Fidyk M, Woods S, et al. Community-associated methicillin-resistant Staphylococcus aureus, Canada. Emerg Infect Dis. 2005;11:844-50. https://doi.org/10.3201/eid1106.041146.

\section{Publisher's Note}

Springer Nature remains neutral with regard to jurisdictional claims in published maps and institutional affiliations.

\section{Ready to submit your research? Choose BMC and benefit from:}

- fast, convenient online submission

- thorough peer review by experienced researchers in your field

- rapid publication on acceptance

- support for research data, including large and complex data types

- gold Open Access which fosters wider collaboration and increased citations

- maximum visibility for your research: over $100 \mathrm{M}$ website views per year

At $\mathrm{BMC}$, research is always in progress.

Learn more biomedcentral.com/submissions 